\title{
Physicochemical Characteristics and QTL Mapping Associated with the Lipid Content of High-Lipid Rice
}

\author{
Na-Hye Kim, Jae-Keun Sohn, Kyung-Min Kim** \\ Division of Plant Biosciences, School of Plant Biosciences, Kyungpook National University, Daegu, South Korea. \\ Email: daffodi124@naver.com, jhsohn@knu.ac.kr, ${ }^{*}$ kkm@knu.ac.kr
}

Received July $17^{\text {th }}, 2013$; revised August $17^{\text {th }}, 2013$; accepted September $10^{\text {th }}, 2013$

Copyright (C) 2013 Na-Hye Kim et al. This is an open access article distributed under the Creative Commons Attribution License, which permits unrestricted use, distribution, and reproduction in any medium, provided the original work is properly cited.

\begin{abstract}
This study was conducted to examine the physicochemical characteristics and perform QTL mapping of genetic factors associated with the lipid content of rice. A rice strain with a high lipid content, "P31-2-2-2-B-B", was developed from mutants of "Dongjin" created by T-DNA insertion. The lipid content of "P31-2-2-2-B-B" brown rice was 4.42\% whereas that of the donor cultivar "Dongjin" was $2.56 \%$. The total fatty acid content of the high-lipid mutant brown rice was $7.82 \%$ and that of "Dongin" was $3.43 \%$. The unsaturated fatty acid composition of the mutant brown rice was $2.73 \%$ oleic acid, $2.74 \%$ linoleic acid, and $0.34 \%$ linolenic acid. In contrast, the fatty acid composition of the donor cultivar "Dongjin" was $1.30 \%$ oleic acid and $0.99 \%$ linoleic acid. The percentage of unsaturated fatty acid to total fatty acid in the high-lipid mutant was higher (74.3\%) than that of "Dongin" (66.8\%). Continuous frequency distribution and transgressive segregation of the lipid content were observed in the $\mathrm{F}_{3}$ family (seeds) derived from a cross between the high-lipid mutant "P31-2-2-2-B-B" and a tongil-type cultivar "Samgang". This result implied that the lipid content was a quantitative trait controlled by a polygene. Additionally, the broad sense heritability of lipid content was estimated to be $89.6 \%$ based on analysis of the $\mathrm{F}_{3}$ seeds. A significant QTL, $q R L C 5$, was identified on chromosome 5 with a LOD score of 2.37, and was flanked by 5007 and 5014. Results of the present study should be useful for improving rice nutritional quality through marker-assisted selection.
\end{abstract}

Keywords: Lipid Content; Fatty Acid Content; Quantitative Trait Loci (QTLs); Rice (Oriza Sativa L.)

\section{Introduction}

Rice is a staple cereal crop for more than half the world's population. In most Asian countries including South Korea, $60 \%-70 \%$ of the daily nutrients are supplied by rice. However, rice consumption has been declining over the years in Asia. It is important to improve the chemical composition and physical properties of rice in order to encourage rice consumption and diversify the use of this grain. Milled rice contains $372 \mathrm{Kcal}$ per $100 \mathrm{~g}$, and is mostly composed of carbohydrates, proteins, and fats [1]. In addition, rice contains nutrients such as numerous minerals and vitamins. Rice lipid is mainly concentrated in the embryo, bran, and aleurone layer. Brown rice is rich in oleic acid, linoleic acid, and various trace components such as $\gamma$-oryzanol, sterols, tocopherol, and tocotorienol [2,3]. In general, lipid content amounts to $1.6 \%-3.02 \%$ at $14 \%$ moisture in brown rice [4-6]. The lipids found in rice, especially unsaturated fatty acids,

${ }^{*}$ Corresponding author. greatly influence grain appearance and quality [3,6-11]. Changes in the crude fat content of rice are associated with aging and deterioration of rice. Oxidation reduces both the total lipid and free fatty acid contents, which are related to the quality of stored rice $[6,9,12]$. Lipids derived from rice enhance the immune system and help to overcome fatigue. Additionally, these lipids reduce serum and LDL cholesterol while elevating HDL cholesterol levels [13-15]. Thus, lipids from rice have been identified as food-derived functional compounds. Heritability of the lipid content in rice is relatively high $(60.90 \%$ $68.25 \%$ ) [7], and has been reported to be a quantitative trait controlled by a polygene $[10,11,16]$. Hu et al. [10] detected three QTLs (Quantitative Trait Loci) on chromosomes 1,2, and 5 associated with the lipid content of rice. Cho et al. [17] identified 12 QTLs on chromosomes 1, 3, 4, 5, 7, 8, and 12. Liu et al. [6] found 14 QTLs related to lipid content on chromosomes 1, 3, and $5-9$. Yu et al. [18] detected four QTLs controlling the lipid content of brown rice on chromosomes 3, 5, 6, and 8. Further- 
more, Qin et al. [3] found QTLs associated with the lipid content of brown rice on chromosomes 1, 2, 3, and 5 - 9 .

In the present study, we analyzed the physicochemical properties and fatty acid composition of a high-lipid mutant rice strain, "P31-2-2-2-B-B". In addition, we identified that QTLs influence lipid content. The results of our investigation may be used as a basis to further develop varieties of high-lipid rice.

\section{Materials and Methods}

\subsection{Plant Materials}

The selected high-lipid rice strain by the bulk and pedigree breeding method, "P31-2-2-2-B-B", derived from "P31" was used for this study. "P31" is a lipid mutant line derived from "Dongjin" by T-DNA insertion from POSTECH (located in Pohang of South Korea) in 2005. Donor cultivar "Dongjin" was also included in our analyses for comparison purposes. Experimental trials were carried out in the experimental plots of Kyungpook National University (KNU) in Gunwi (South Korea) from 2007 to 2010 . One plant per hill was transplanted with 30 $\mathrm{cm}$ between rows and $15 \mathrm{~cm}$ between plots. Field management was conducted according to the normal cultivation practices recommended by Rural Development Administration (RDA) of South Korea with an application for fertilizer $\left(\mathrm{N}_{-} \mathrm{P}_{2} \mathrm{O}_{5}-\mathrm{K}_{2} \mathrm{O}\right)$ at the rate of 90,45 , and 57 $\mathrm{kg} \cdot \mathrm{ha}^{-1}$.

\subsection{Analysis of Rice Chemical Content}

Damage, red, green, and broken grains of the brown rice were removed before the test. The amylose, lipid, protein, and starch contents of the brown rice for three replication per each line was determined with near-infrared spectroscopy (NIRS) using a spectrophotometer (Foss 6500). Crude fat and fatty acid contents were analyzed by the Local Innovation Center of KNU. To extract crude fat from the rice, the Soxhlet extraction method was used with ethyl ether as a solvent. To recover fatty acids, a methanol:heptane:benzene:2,2-dimethozypropane: $\mathrm{H}_{2} \mathrm{SO}_{4}$ solution (37:36:20:5:2, v:v:v:v) was added to $300 \mathrm{mg}$ of each of rice powder sample. After heating to $80^{\circ} \mathrm{C}$, the single phase was cooled to room temperature. Fatty acid composition was measured using a previously described method [19] which involved preparing fatty acid methyl esters by direct transmethylation and analyzing them with a gas chromatography instrument (Agilent $6890 \mathrm{~N}$ ). Detailed running conditions for the GC were also previously described [20].

\subsection{Analysis of Genetic Factors Associated with Lipid Content}

To evaluate the broad sense heritability of lipid content, the $F_{3}$ family, which consisting of 170 plants derived from a cross between japonica variety "P31-2-2-2-B" and tongil-type cultivar "Samgang" cultivated in a greenhouse at KNU during the winter of 2010, was evaluated. Lipid contents of the rice were evaluated by NIRS using a spectrophotometer (Foss 6500). T-test of $\mathrm{F}_{3}$ family was calculated by the program of SAS 9.1.

\subsection{QTL Analysis to Identify Factors Associated with Lipid Content}

The mapping population consisted of 90 lines $\left(\mathrm{F}_{2}\right.$ population), derived from a cross between "P31-2-2-2-B" (japonica) and "Samgang" (Tongil-type). The molecular marker data were essentially the same as described in Qin et al. [3], which consisted of 56 simple sequence repeats (SSR) and 116 sequence tagged site (STS) markers covering 12 chromosomes. A genetic linkage map with one SSR and eight STS markers was created using MAPMAKER/EXP version 3.0 [21]. WinQTL cart 2.5 [22] and QTLMAPPER version 1.6 [11] were used for the QTL analysis. Composite interval mapping (CIM) was operated for the whole genome scanning on QTLs detection by one thousand permutation test at a 0.05 significant level at a threshold of LOD2.0 [22]. QTL nomenclature used in our study was previously described by McCouch et al. [23].

\section{Results}

\subsection{Analysis of Rice Chemical Content}

Chemical content of the high-lipid mutant "P31-2-2-2B-B" rice determined by NIRS is shown in Table 1. The amylose and starch contents of "P31-2-2-2-B-B" brown rice $(22.57 \%$ and $73.39 \%$, respectively) were higherthan those of the donor cultivar "Dongjin" $(20.32 \%$ and $71.44 \%$, respectively). Lipid level in the high-lipid mutant was about 1.6 times higher $(3.00 \%)$ than that of "Dongjin" (1.83\%). Crude fat content of the high-lipid mutant 'P31-2-2-2-B-B' rice determined by the Soxhlet method was about 1.7 times higher $(4.42 \%)$ than that of "Dongjin" rice $(2.56 \%)$. The fatty acid compositions of "P31-2-2-2-B-B" and "Dongjin" were measurably different (Table 2). The oleic acid and linoleic acid contents of "P31-2-2-2-B-B" were $2.73 \%$ and $2.74 \%$ respectively, which was about 2.1 and 2.8 times higher than the levels found in "Dongjin" ( $1.30 \%$ and $0.99 \%$, respectively). The linolenic acid content of "P31-2-2-2-B-B" was $0.34 \%$; this was not measured in the donor cultivar "Dongjin" The ratio of unsaturated fatty acids to total fatty acidsin "P31-2-2-2-B-B" was relatively higher $(74.3 \%)$ than that of "Dongjin" (66.8\%).

\subsection{Analysis of Genetic Factors Associated with Lipid Content}

Continuous frequency distribution and transgressive 
Table 1. Chemical contents of the high-lipid mutant "P31-22-2-B-B" and "Dongjin" brown rice.

\begin{tabular}{ccccc}
\hline \multirow{2}{*}{ Cultivar } & \multicolumn{4}{c}{ Chemical content $(\%)^{\mathrm{a}}$} \\
\cline { 2 - 5 } & Amylose & Lipid & Protein & Starch \\
\hline P31-2-2-2-B-B & $22.57 \pm 0.75^{\mathrm{b}}$ & $3.00 \pm 0.16$ & $8.05 \pm 0.54$ & $73.39 \pm 0.62$ \\
Dongjin & $20.32 \pm 0.44$ & $1.83 \pm 0.08$ & $8.25 \pm 0.15$ & $71.44 \pm 0.73$ \\
\hline
\end{tabular}

${ }^{\mathrm{a}}$ Measured by NIRS. ${ }^{\mathrm{b}}$ Data are presented as the mean \pm SD.

Table 2. Crude fat contents of the high-lipid mutant "P31-22-2-B-B" and "Dongjin" brown rice.

\begin{tabular}{ccc}
\hline Cultivar & Crude fat content $(\%)^{\mathrm{a}}$ & Ratio \\
\hline P31-2-2-2-B-B & $4.42 \pm 0.17^{\mathrm{b}}$ & 1.73 \\
Dongjin & $2.56 \pm 0.28$ & 1.00 \\
\hline
\end{tabular}

${ }^{\mathrm{a}}$ Measured by the Soxhlet method. ${ }^{\mathrm{b}}$ Data are presented as the mean $\pm \mathrm{SD}$.

segregation of lipid content were observed in seeds from the $\mathrm{F}_{3}$ family derived from a cross between the high-lipid japonica variety "P31-2-2-2-B-B" strain and tongil-type cultivar "Samgang" (Figure 1). The approximately normal distribution was observed, indication quantitative inheritance of lipid content. T-test results showed that there were significant differences in lipid content between the two parental lines. A lipid content value ranged from $1.72 \%$ to $3.29 \%$ in the $\mathrm{F}_{3}$ has relatively high broad sense heritability (89.6\%; Table 3).

\subsection{QTL Analysis of Factors Affecting Lipid Content}

A QTL specific for lipid content was detected on chromosome 5. QTL a $q R L C 5$ was located on chromosome 5 between markers 5007 and 5014 with an LOD score of 2.37 , accounting for $20.0 \%$ of the phenotypic variation. At this locus, alleles from the "P31-2-2-2-B-B" parent strain increased the lipid content by $0.12 \%$ (Figure 2, Table 4).

\section{Discussion}

The lipid content of rice is low and most is composed of unsaturated fatty acids. Additionally, according to the previous report, the lipid content of rice material increases the immune system and improves HDL level [1315]. In the present study, crude fat content of the highlipid mutant "P31-2-2-2-B-B" determined by the Soxhlet method was about 1.7 times higher than that of "Dongjin" (Table 5). Differences in composition between the two rice strains observed this analysis (Table 5) are similar to the ones found with NIRS. The total fatty acid level in "P31-2-2-2-B-B" was greater (7.82\%, about 2.3 times) than that of "Dongjin" (3.43\%). Similarly, "P312-2-2-B-B" had a high concentration of total unsaturated fatty acids (5.81\%) which was about 2.5-times higher
Table 3. Fatty acid composition of the high-lipid mutant “P31-2-2-2-B-B" and "Dongjin” brown rice.

\begin{tabular}{ccc}
\hline $\begin{array}{c}\text { Fatty acid composition } \\
(\%)\end{array}$ & $\begin{array}{c}\text { P31-2-2-2-B-B } \\
(\% \text { total })\end{array}$ & $\begin{array}{c}\text { Dongjin } \\
(\% \text { total })\end{array}$ \\
\hline Saturated fatty acids & & \\
Palmitic acid, $\mathrm{C}_{16: 0}$ & $1.55 \pm 0.02^{\mathrm{a}}(19.8)$ & $0.78 \pm 0.04(22.7)$ \\
Stearic acid, $\mathrm{C}_{18: 0}$ & $0.46 \pm 0.006(5.9)$ & $0.36 \pm 0.02(10.5)$ \\
$\quad$ Subtotal & $2.01 \pm 0.03(25.7)$ & $1.14 \pm 0.06(33.2)$ \\
Unsaturated fatty acids & & \\
Oleic acid, $\mathrm{C}_{18: 1}$ & $2.73 \pm 0.04(34.9)$ & $1.30 \pm 0.06(37.9)$ \\
Linoleic acid, $\mathrm{C}_{18: 2}$ & $2.74 \pm 0.04(35.0)$ & $0.99 \pm 0.08(28.9)$ \\
Linolenic acid, $\mathrm{C}_{18: 3}$ & $0.34 \pm 0.004(4.3)$ & - \\
Subtotal & $5.81 \pm 0.08(74.3)$ & $2.29 \pm 0.14(66.8)$ \\
Total & $7.82 \pm 0.11(100)$ & $3.43 \pm 0.20(100)$ \\
\hline
\end{tabular}

${ }^{\mathrm{a}}$ Data are presented as the mean $\pm \mathrm{SD}$.

Table 4. Lipid content and heritability estimated from the analysis of $F_{3}$ seeds produced by a cross between the highlipid "P31-2-2-2-B-B" mutant rice and tongil-type cultivar "Samgang".

\begin{tabular}{cc}
\hline Cultivar & Lipid content $(\%)$ \\
\hline P31-2-2-2-B-B $\left(\mathrm{P}_{1}\right)$ & $3.25 \pm 0.05^{* *}$ \\
Samgang $\left(\mathrm{P}_{2}\right)$ & $2.08 \pm 0.01$ \\
$\mathrm{~F}_{3}$ seeds & \\
Mean $\pm \mathrm{SD}$ & $2.32 \pm 0.13$ \\
Range & $1.72-3.29$ \\
$\mathrm{H}_{\mathrm{B}}^{2}$ & 89.6 \\
\hline
\end{tabular}

Data are presented as the mean $\pm \mathrm{SD}$. ${ }^{* *}$ Indicates significant difference at a level of $1 \%$. $\mathrm{H}_{\mathrm{B}}^{2}=\left\{\mathrm{V}_{\mathrm{F} 3}-1 / 2\left(\mathrm{~V}_{\mathrm{P} 1}+\mathrm{V}_{\mathrm{P} 2}\right)\right\} / \mathrm{V}_{\mathrm{F} 3} * 100 \%$.

Table 5. QTL locations and biometrical parameters associated with the lipid content of rice.

\begin{tabular}{cccccc}
\hline QTL & $\begin{array}{c}\text { Interval } \\
\text { markers }\end{array}$ & LOD & $\mathrm{R}^{2}(\%)^{\mathrm{a}}$ & $\mathrm{A}^{\mathrm{b}}$ & Increasing allele \\
\hline qRLC5 & $5007-5014$ & 2.37 & 20.0 & 0.12 & P31-2-2-2-B-B \\
\hline
\end{tabular}

${ }^{a} R^{2}$ : Percentage of phenotypic variation explained. ${ }^{b} A$ : a positive value indicates the genotype from the parent "P31-2-2-2-B-B" toward increasing the trait value.

than that observed in "Dongjin" (Table 2). The percentages of each fatty acid relative to the total fatty acid levels in "P31-2-2-2-B-B" were $19.8 \%$ for palmitic acid, $34.9 \%$ for oleic acid, and $35.0 \%$ for linoleic acid. Similar results were reported by the USDA [24], Choi et al. [25], and Koshen [26]. However, the percentage of linolenic acid in the high-lipid strain observed in the current study was higher $(4.3 \%)$ than that previously reported by the USDA $(1.5 \% ; 1998)$. In this study, lipid content was a quantitative trait controlled by a polygene as previously 


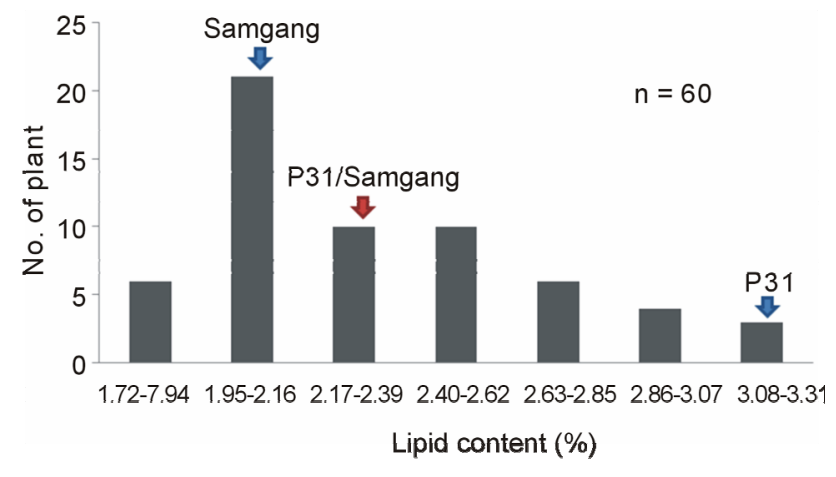

Figure 1. Frequency distribution of lipid contents in $F_{3}$ seeds from a cross between the high-lipid "P31-2-2-2-B-B" mutant and tongil-type cultivar "Samgang".

Chr. 5

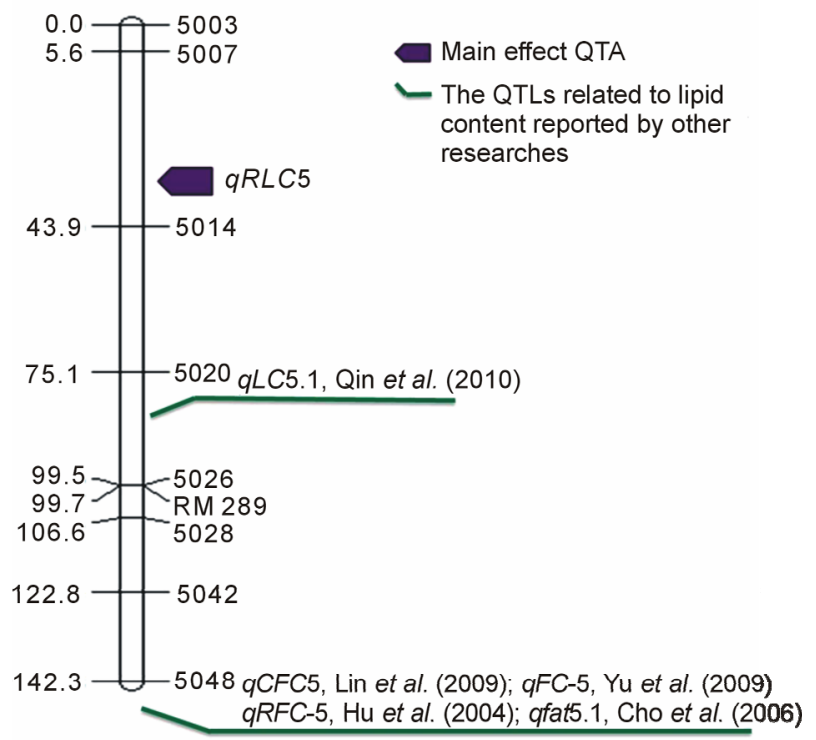

Figure 2. Chromosomal locations of QTLs associated with the lipid content of rice.

reported by Kang et al. [16], Chen et al. [9], and Hu et al. [10]. However, Qi et al. [7] reported that the broad sense heritability was $60.90 \%-68.25 \%$. Compared to this previous study, the result $(89.6 \%)$ obtained in our investigation should be higher due to the different genotype and smaller number of samples. Thus, more stable heritability will be estimated from the larger number of samples in a future study. The interval distance of $q R L C 5$ between 5007 and 5014 observed in the present study was relatively wide $(38.3 \mathrm{cM})$. This was due to a small number of markers. If we were to perform this analysis using more polymorphic markers, the distance of between the $q R L C 5$ markers would be narrow. As shown in Figure 2, qRLC5 was detected at a location different from the one reported by Qin et al. [3]. Additionally, previous studies were detected to analyze QTL of lipid content after marker 5048 loci $[6,10,17,18]$. Therefore, fine mapping of chromo- some 5 could enable us to identify QTLs with high average LOD scores that affect lipid content. In the present study, we analyzed the physicochemical properties of a high-lipid mutant strain and identified QTLs that influence lipid content. This result may be used as a basis to further develop varieties of high-lipid rice and improve rice nutritional quality through marker-assisted selection.

\section{Acknowledgements}

This work was supported by a grant from the Next-Generation BioGreen 21 Program (No. PJ0080912013), Rural Development Administration, Republic of Korea.

\section{REFERENCES}

[1] J. S. Geum, "Nutrition of Rice and Processed Rice Products," Food Preservation and Processing Industry, Vol. 9, No. 1, 2010, pp. 55-60.

[2] B. O. Juliano, "Rice Chemistry and Quality, Nutritive Value of Rice and Rice Diets," 3rd Edition, Philippine Rice Research Institute, Manila, 2003, pp. 169-175.

[3] Y. Qin, S. M. Kim, X. H. Zhao, H. S. Lee, B. Jia, K. M. Kim, M. Y. Eun and J. K. Sohn, "QTL Detection and MAS Selection Efficiency for Lipid Content in Brown Rice (Oryza sativa L.)," Genes \& Genomics, Vol. 32, No. 6, 2010, pp. 506-512. http://dx.doi.org/10.1007/s13258-010-0026-5

[4] A. P. Resurreccion, B. O. Juliano and Y. Tanaka, "Nutrient Content and Distribution in Milling Fractions of Rice Grain," Journal of the Science of Food and Agriculture, Vol. 30, No. 5, 1979, pp. 475-481. http://dx.doi.org/10.1002/jsfa.2740300506

[5] R. J. B. Heinemann, P. L. Fagundes, E. A. Pinto, M. V. C. Penteado and U. M. Lanfer-Marquez, "Comparative Study of Nutrient Composition of Commercial Brown, Parboiled and Milled Rice from Brazil," Journal of Food Composition and Analysis, Vol. 18, No. 4, 2005, pp. $287-$ 296. http://dx.doi.org/10.1016/j.jfca.2004.07.005

[6] W. Liu, J. Zeng, G. Jiang and Y. He, "QTLs Identification of Crude Fat Content in Brown Rice and Its Genetic Basis Analysis Using DH and Two Backcross Populations,' Euphytica, Vol. 169, No. 2, 2009, pp. 197-205. http://dx.doi.org/10.1007/s10681-009-9922-7

[7] Z. B. Qi, B. J. Li, W. G. Yang and X. F. Wu, "A Study on The Genetic of Exterior Quality and Fat of the Rice Grains," Acta Genetica Sinica, Vol. 10, No. 6, 1983, pp. 452-458.

[8] S. Z. Wu, C. W. Huang, L. C. Ou and J. Z. Liu, "Studies on Varietal Characteristics in Culture of Oryza Sativa. III. A Study on Grain Quality Character of Rice Varieties," Science Agricultural Sinica, Vol. 18, No. 5, 1985, pp. 1-7.

[9] J. G. Chen and J. Zhu, "Genetic Analysis of Fat Content in Indica-Japonica Intersubspecific Hybrid Rice (Oryza sativa L.)," Journal of Tropical and Subtropical Botany, Vol. 6, No. 4, 1998, pp. 347-351.

[10] Z. L. Hu, P. Li, M. Q. Zhou, Z. H. Zhang, L. X. Wang, L. 
H. Zhu and Y. G. Zhu, "Mapping of Quantitative Trait Loci (QTLs) for Rice Protein and Fat Content Using Doubled Haploid Lines," Euphytica, Vol. 135, No. 1, 2004, pp. 47-54.

http://dx.doi.org/10.1023/B:EUPH.0000009539.38916.32

[11] H. L. Wang, X. Y. Wan, J. C. Bi, J. K. Wang, L. Jiang, L. M. Chen, H. Q. Zhai and J. M. Wan, "Quantitative Analysis of Fat Content in Rice by Near-Infrared Spectroscopy Technique," Cereal Chemistry, Vol. 83, No. 4, 2006, pp. 402-406. http://dx.doi.org/10.1094/CC-83-0402

[12] Z. K. Zhou, K. Robards, S. Helliwell and C. Blanchard, "Ageing of Stored Rice: Changes in Chemical and Physical Attributes," Journal of Cereal Science, Vol. 35, No. 1, 2002, pp. 65-78. http://dx.doi.org/10.1006/jcrs.2001.0418

[13] A. A. Qureshi, N. Qureshi, J. Wright, Z. Shen, G. Kramer, A. Gapor, Y. Chong, G. DeWitt, A. Ong, D. Peterson and B. Bradlow, "Lowering of Serum Cholesterol in Hypercholesterolemic Humans by Tocotrienols (Palmvitee)," American Journal of Clinical Nutrition, Vol. 53, No. 4S, 1991, pp. 1021s-1026s.

[14] T. A. Wilson, L. M. Ausman, C. W. Lawton, D. M. Hegsted and R. J. Nicolosi, "Comparative Cholesterol Lowering Properties of Vegetable Oils: Beyond Fatty Acids," Journal of the American College of Nutrition, Vol. 16, No.5 , 2000, pp. 601-607. http://dx.doi.org/10.1080/07315724.2000.10718957

[15] R. Cheruvanky, "Phytochemical Products: Rice Bran," In: Phytochemical Functional Foods, CRC Press, New York, 2003, pp. 347-376. http://dx.doi.org/10.1533/9781855736986.2.347

[16] H. J. Kang, Y. G. Cho, Y. T. Lee, Y. D. Kim, M. Y. Eun and J. U. Shim, "QTL Mapping of Genes Related with Grain Chemical Properties Based on Molecular Map of Rice," Korean Journal of Crop Science, Vol. 43, No. 4, 1998, pp. 199-204.

[17] Y. G. Cho, H. J. Kang, Y. T. Lee, S. R. McCouch and M. Y. Eun, "QTL Analysis of Rice Quality Using a Recombinant Inbred Population," Journal of Agricultural Science Chungbuk Nat'l Univ., Vol. 23, 2006, pp. 147-164.
[18] Y. H. Yu, G. Li, Y. Y. Fan, K. Q. Whang, J. Min, Z. W. Zhu and J. Y. Zhuang, "Genetic Relationship between Grain Yield and the Contents of Protein and Fat in a Recombinant Inbred Population of Rice," Journal of Cereal Science, Vol. 50, No. 1, 2009, pp. 121-125. http://dx.doi.org/10.1016/j.jcs.2009.03.008

[19] K. S. Liu, E. A. Brown and F. T. Orthoefer, "Fatty Acid Composition within Each Structural Part and Section of a Soybean Seed," Journal of Agricultural and Food Chemistry, Vol. 43, No. 2, 1995, pp. 381-383. http://dx.doi.org/10.1021/jf00050a023

[20] K. S. Liu, F. T. Orthoefer and E. A. Brown, "Association of Seed Size with Genotypic Variation in the Chemical Constituents of Soybeans," Journal of the American Oil Chemists' Society, Vol. 72, No. 2, 1995, pp. 189-192.

[21] S. Lincoln, M. Daly and E. S. Lander, "Constructing Genetic Maps with MAPMAKER/EXP 3.0," Whitehead Institute Technical Report, 2nd Edition, Whitehead Institute, Cambridge, 1992

[22] Z. B. Zeng, "Precision Mapping of Quantitative Trait Loci," Genetics, Vol. 136, No. 4, 1994, pp. 1457-1468.

[23] S. R. McCouch, Y. G. Cho, M. Yano, E. Paul, M. Blinrub, H. Morishima and T. Kinoshita, "Rice Report on QTL Nomenclature," 2003. http://www.gramene.org/newsletters.

[24] USDA, "A Nutrient Database for Standard Reference. Release 12," Nutrient Data Laboratory, US Department of Agric Beltville Nutrition Research Center, Riverdale, 1998.

[25] J. S. Choi, H. H. Ahn and H. J. Nam, "Comparison of Nutritional Composition in Korean Rices," Journal of the Korean Society of Food Science and Nutrition, Vol. 31, No. 5, 2002, pp. 885-892. http://dx.doi.org/10.3746/jkfn.2002.31.5.885

[26] L. Keshun, "Comparison of Lipid Content and Fatty Acid Composition and Their Distribution within Seeds of 5 Small Grain Species," Journal of Food Science, Vol. 76, No. 2, 2011, pp. 332-342. 